\title{
Da sociedade esportiva moderna no Brasil à constituição de um sportsman do sertão norte-mineiro
}

\author{
From the Modern Sport Society in Brazil to the Making of a North \\ Minas Backcountry Sportsman
}

\author{
Rogério Othon Teixeira Alves \\ Universidade Estadual de Montes Claros, Montes Claros/Brasil \\ Doutor em Estudos do Lazer, UFMG \\ rogerioothon@gmail.com \\ Luciano Pereira da Silva \\ Universidade Federal de Minas Gerais, Belo Horizonte/Brasil \\ Doutor em Educação, UFGM
}

\begin{abstract}
Resumo: Neste artigo, pretende-se, a partir do entendimento da composição histórica própria e diversificada do cenário esportivo brasileiro, compreender a forja de um sportsman que atuaria na cidade de Montes Claros, região sertaneja que não compreendeu os aspectos da modernidade no ritmo das capitais, mas que, também, não esteve alheia a eles. Como estratégia metodológica, foram utilizados como fontes obras de memorialistas montes-clarenses e periódicos cariocas e mineiros, principalmente do final do século XIX e início do século XX. Ari de Oliveira, após o seu retorno do Rio de Janeiro, lugar onde conviveu numa sociedade em ebulição esportiva, em função do seu envolvimento como atleta amador e dirigente das equipes que participara em Montes Claros, constituiu-se num sportsman local, refletindo o esporte da cidade grande para o interior, praticando e promovendo o futebol.
\end{abstract}

PalaVRAS-Chave: História; Montes Claros/MG; Esporte; Futebol; Sportsman.

ABSTRACT: Based on the understanding of its own and diverse historical composition of the Brazilian sport scenario, this piece aims to comprehend the making of a sportsman who would act in the city of Montes Claros, a backcountry region that has not encompassed the modernity aspects in the same pace as the big cities have, but it has also not been oblivious to them. As for methodological strategy, pieces by memoir writers from Montes Claros and Rio de Janeiro journals were used as sources, mainly the ones from the late nineteenth- and early twentieth-century. After his return from Rio de Janeiro, where he had experienced a sporting outburst society, Ari de Oliveira became a sportsman, due to his engagement as an amateur athlete and as a sport manager leading the teams back in Montes Claros, bringing the sport of the big cities to the countryside, practicing and promoting football.

KEYWORDS: History; Montes Claros/MG; Sport; Football; Sportsman. 


\section{INTRODUÇÃo}

Para iniciar este texto, como referência, pretende-se partir do entendimento prévio que abarca o que se convencionou a chamar de Modernidade, período de tempo que "refere-se a estilo, costume de vida ou organização social que emergiram na Europa a partir do século XVII e que ulteriormente se tornaram mais ou menos mundiais em sua influência". 1

A partir da indicação de Guiddens (1991), além da insígnia europeia, no tempo permitido por cada região, houve um processo de modernização feita de forma gradual da infraestrutura que "mudaria não só o cenário urbano como o cotidiano dos habitantes destes centros urbanos". ${ }^{2}$ No Brasil não seria diferente, principiando nas grandes cidades, notadamente no Rio de Janeiro.

Da capital brasileira do século XIX, a ideia e, quando possível, o processo de modernização urbana irradiara-se pelo país. Outras cidades também foram sensíveis às inovações europeias, porém, no Rio de Janeiro, como indica Barbosa (2007), tais transformações urbanas foram mais manifestas naquele momento:

O cinematógrafo, o fonógrafo, o gramofone, os daguerreotipos, a linotipo, as Marinonis são algumas das tecnologias que invadem a cena urbana e o imaginário social na virada do século XIX para o XX, introduzindo amplas transformações no cenário urbano e nos periódicos que circulam na cidade. ${ }^{3}$

Como desdobramento do processo de modernização, constata-se nos séculos XIX e XX, a constituição de um campo esportivo em diversas partes do mundo e no Brasil. Desde o início, a prática esportiva esteve associada às noções de civilização e progresso que advinham da Europa. Para esse viver moderno, "implicava necessariamente relacionar-se com a tecnologia e ter atitudes individualistas, como também uma associação a símbolos cosmopolitas, em especial aqueles que conotam origem europeia consolidando a prática de ser chic e snob". 4 No Brasil, "tratava-se de emular o que havia de melhor nos países civilizados numa nação recém-

\footnotetext{
1 GIDDENS. As consequências da modernidade, p. 11.

${ }^{2}$ LIMA. Da chegada a institucionalização: os primeiros passos do futebol pernambucano, p. 1.

${ }^{3}$ BARBOSA. História cultural da imprensa: Brasil 1900-2000, p. 21.

${ }^{4}$ SEVCENKO. A capital irradiante: técnica, ritmos e ritos do Rio, p. 580.
} 
independente que arvorava apresentar sua adesão à ideia de progresso. ${ }^{5}$ Por fim, como parte do contexto moderno, o esporte de uma forma geral e, por conseguinte, o futebol, acabou exercendo um papel de instrumento de modernização do país.

A rápida popularização do esporte notada no Brasil, iniciada nas grandes cidades, seguiu um modelo inglês. Foi a partir da Inglaterra que "[...] logo a prática esportiva desembarcou em outros países no seio dos contatos materiais e simbólicos que marcaram fortemente o século XIX com seus navios a vapor e comércio mundial". ${ }^{6}$ Possivelmente, cada cidade atingida por esse novo modo de vida, seguiu um processo de aculturação próprio ao sofrer as influências externas.

Importante frisar que, o ritmo de cada cidade, de se tornar pretensamente moderna, era próprio, obedecendo às peculiaridades regionais, porém, ainda assim, "[...] foi se instituindo a valorização das novidades que vinham do exterior, notadamente da Europa, uma postura que se tornou denotada nos jornais, inclusive como estratégia publicitária".7

Entendendo que o Rio de Janeiro se tornou uma das cidades que refletiram o esporte inglês para o interior, naturalmente foi emergindo a figura de pessoas públicas que praticavam e organizavam as ações e eventos esportivos modernos:

Em meados do século XIX, um personagem começava a se fazer mais presente no cotidiano da capital do Brasil recém-independente: o homem público, que valorizava as experiências vividas nos mais diversos cenários sociais que se delineavam numa cidade cada vez mais dinâmica. A emergência dessa personalidade (uma nova postura, por vezes mesmo um estilo de vida) tem relação com o momento pelo qual passava o país. ${ }^{8}$

A partir do surgimento do "homem público" indicado por Victor Melo (2015), ${ }^{9}$ notar-se-ia a configuração paulatina do sportsman. ${ }^{10} 0$ termo sportsmen é uma expressão inglesa que inicialmente designava os adeptos da caça por diversão. Como exemplo do uso do vocábulo, no Brasil, em texto do jornal The Rio Herald, que

\footnotetext{
${ }^{5}$ MELO. Entre a elite e o povo: o sport no Rio de Janeiro do século XIX (1851-1857), p. 213.

${ }^{6}$ MELO. O esporte como forma de lazer no Rio de Janeiro do século XIX e década inicial do XX, p. 50.

${ }^{7}$ MELO; SANTOS. Deslizando rumo ao progresso: a patinação em São Paulo (1877-1912), p. 172.

${ }^{8}$ MELO. O esporte: uma diversão no rio de janeiro do século XIX, p. 50.

${ }^{9}$ MELO. O esporte: uma diversão no rio de janeiro do século XIX, 2015.

${ }^{10}$ Sportsman (plural: sportsmen) é uma palavra da língua inglesa que se traduz para o português "esportista" ou "desportistas". Porém, no final do século XIX e início do século XX designava os sujeitos da elite que se achavam modernos e distintos ao emular práticas esportivas notadas na Europa (JEUKEN. Esporte na primeira república: a história do espetáculo, 2017).
} 
narra uma viagem do Rio de Janeiro para Minas Gerais em 1824, o autor, provavelmente um inglês, enquanto passava pela região de Barbacena-MG, descreve a vista da cidade como linda e que era uma pena não haver sportsmen, porque, pela quantidade abundante de animais, é o melhor país para caça que ele já vira: "Perdizes, codornas e todos os tipos de jogos mais estimados são de grande abundância, e são susceptíveis a permanecer assim, porque não existem atualmente desportistas para molestá-los. Este é o melhor país para atirar e caçar que já vi”.11

Já em meados do século XIX, a palavra "sportsmen", à época, indicava uma "linguagem hypica moderna",12 e estava comumente associada aos "amadores de corridas de cavalos" (Fig. 1).

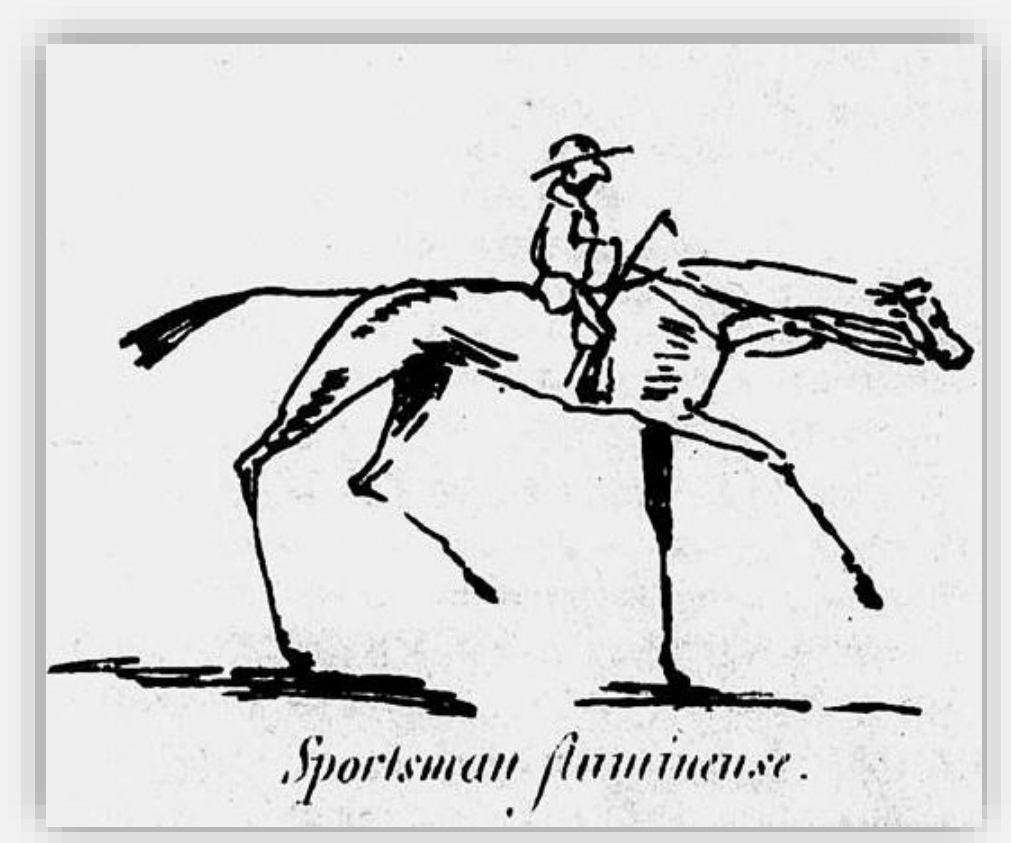

Fig. 1 - Imagem representativa de um sportsman de meados do século XIX. Illustração Brazileira, fevereiro de 1854, p. 31.

Entretanto, com o passar dos anos, enquanto a sociedade se constituía poliesportiva, sportsmen também se vinculava aos sujeitos que participavam

11 Tradução nossa. THE RIO HERALD. Rio de Janeiro, p. 4, 15 março 1824. "The view of the country round Barbacena is beautiful, altho the want of buildings is to be regretted. Partridges, Quails, and all kind of the most esteemed game are in great abundance, and are likely to remain so, because there ate at present no sportsmen. This is the finest country for shooting and hunting I ever saw".

${ }^{12}$ NOVO CORREIO DAS MODAS. Rio de Janeiro, p. 192, edição 2, 1853. 
diretamente da rotina esportiva, normalmente atletas e dirigentes das agremiações, ligas e clubes esportivos que surgiam pelo país, no final do século XIX e decorrer do $\mathrm{XX}$. Assim, a questão aqui pretendida é o surgimento dessas pessoas que, de uma forma ou de outra, disseminaram os esportes pelo país; normalmente, personagens da elite e amadores.

Especificamente em relação ao futebol, esporte que mais se difundiu no Brasil, nota-se que também teve os seus sportsmen, personagens para introdução e desenvolvimento nas grandes cidades. Consta que muitos desses sujeitos eram jovens, filhos da elite que, por terem estudado e convivido com o futebol na Europa, trouxeram as suas bases para o Brasil. Entre eles, destacam-se: Charles Miller, que regressou da Inglaterra para São Paulo em 1895, com as regras e equipamentos do futebol; ${ }^{13}$ Oscar Cox, que desembarcou no Rio de Janeiro em 1901, juntamente com o conhecimento do futebol, vindo da Suíça; ${ }^{14}$ Zuza Ferreira, que retornou da Inglaterra para Salvador em 1901, com bolas e manual de regras; ${ }^{15}$ e Guilherme de Aquino, que em 1903 "traz consigo uma bola, meiões, camisas e outros materiais utilizados na prática do cricket, rugby, tenis e do foot-ball association" para Recife. ${ }^{16}$

Antes de avançar, já é possível afirmar que a narrativa literária estabelecida para as histórias do futebol no Brasil é academicamente contestável. Segundo Melo, "ao aprofundar e ampliar os olhares sobre o futebol, coloca-se em xeque essa busca desenfreada pelas origens". ${ }^{17}$ Entende-se, então, que o processo de desenvolvimento do futebol foi multifacetado, composto pelos diversos vieses inerentes a cada região brasileira.

Finalmente, os sportsmen anteriormente citados, participaram da introdução e desenvolvimento do futebol nas suas respectivas cidades, atuando com destaque. Assim, identificá-los e reconhecê-los é relevante para a ampliação da discussão do contexto histórico social do Brasil, porém, seria uma precipitação afirmar que agiram sozinhos; ou que o futebol brasileiro obedecera sempre e unicamente ao

\footnotetext{
${ }^{13}$ MÁXIMO. Memórias do futebol brasileiro, 1999.

${ }^{14}$ FERNADEZ. Futebol, identidades e representações: caso do Fluminense Football Club, 2009.

${ }^{15}$ SANTOS. Entre negros e brancos: considerações sobre a formação da cultura futebolística em Salvador, 2009.

${ }^{16}$ LIMA. Da chegada a institucionalização: os primeiros passos do futebol pernambucano, p. 6.

17 MELO. Evidência e especulação: a origem do futebol no Rio de Janeiro (1898-1902), p. 920.
} 
enredo do jovem estudante da elite que retornava da Europa. Contrariando tal explicação histórica generalizadora, Dias diz que:

Cidades às vezes distantes do que se supõe o centro irradiador de um ideário de progresso, pouco ou nada urbanizadas, conheceram também, ainda que à sua maneira, uma sociabilidade ligada aos esportes. Isso difere, portanto, da imagem de isolamento, que tão caracteristicamente marca as representações sobre o sertão brasileiro. ${ }^{18}$

Pretende-se, enfim, a partir do entendimento da composição histórica diversificada do cenário esportivo brasileiro, compreender a forja de um sportsman que atuaria no interior, precisamente na cidade de Montes Claros, Norte de Minas Gerais, região sertaneja que não abarcou os aspectos da modernidade no ritmo das capitais, mas que, também, não esteve alheia a eles.

Ari de Oliveira, sujeito-objeto desta pesquisa, se não introduziu o futebol em Montes Claros, o promoveu de diversas formas, assumindo as características marcantes dos sportsmen, participando ativamente da sua rotina nos primeiros anos desse esporte na cidade.

Ainda que os ventos da modernidade chegassem ao sertão mineiro com certo atraso, sugerir simples isolamento desse período da história é algo improvável, pois, mesmo situada numa região de difícil acesso e afastada das capitais, não pressupunha estagnação ao ponto de distanciar-se dos assuntos da época. ${ }^{19}$ Assim, é importante dizer que, essas transformações não aconteceriam sem a articulação de sujeitos "modernos", que traziam de outras paragens, informações para o advento de novos hábitos e costumes, aos poucos assimilados pela população.

Assim se daria o início das práticas esportivas nas cidades, principalmente do futebol. A cidade de Montes Claros, de considerável importância e influência no Norte de Minas, recebeu a experiência de práticas pertencentes ao ideário da modernidade mais lentamente. Porém, no tempo permitido, a prática e assistência do futebol, passou "[...] paulatinamente a compor o cotidiano da cidade, configurando-se como uma das principais vivências de diversão do município". ${ }^{20}$

\footnotetext{
${ }^{18}$ DIAS. O esporte e a cidade na historiografia brasileira: uma revisão crítica, p. 35.

${ }^{19}$ SILVA. O futebol e o início da diversão esportivizada em Montes Claros-MG, p. 2.

20 SILVA. O futebol e o início da diversão esportivizada em Montes Claros-MG, p. 3.
} 
Para fomentar tais aspectos que transformariam a cena urbana, um conjunto de fatores seria necessário, entre eles, destaca-se a imprensa. 0 primeiro jornal de Montes Claros surgiu em 1884, mas seria em 1918 que a cidade ganharia o primeiro jornal longevo e de destacada atuação por mais de 40 anos: a Gazeta do Norte.

A Gazeta do Norte comportaria o sportsman de Montes Claros, Ari de Oliveira, por muitos anos. Entretanto, como hipótese, conjectura-se que tal tessitura do citado sportsman deveu-se à sua formação familiar e estudantil, principalmente no período em que residira no Rio de Janeiro, tempo de oportunidades diferenciadas, antes de atuar profissionalmente no jornal fundado por seu pai, José Tomaz de Oliveira.

Como método investigativo, para a construção identitária de Ari de Oliveira, foi preciso pesquisar e analisar obras de memorialistas da região e periódicos mineiros e cariocas do final do século XIX e início do século XX. Para isso, antes mesmo do nascimento do personagem tema da pesquisa, foi necessário emergir na origem do seu pai, possivelmente o seu maior incentivador. Assim, interessaram os aspectos familiares, profissionais e do divertimento de Ari de Oliveira e família, a fim de concluir a sua caracterização como um sportsman.

\section{JoSÉ TOMAZ DE OLIVEIRA: FUNDADOR DA GAZETA DO NORTE}

José Thomaz de Oliveira nasceu em Recife/PE, no ano de 1875, e no período em que se bacharelava em Ciências Jurídicas e Sociais na tradicional Faculdade de Direito de Recife, trabalhou no Jornal do Recife. No mês seguinte à sua formatura, em dezembro de 1895, assumiria o cargo de Promotor de Justiça na comarca de Carmo do Paranaíba no estado de Minas Gerais. ${ }^{21}$ Em 19 de junho de 1898, o jornal Minas Geraes publicaria nomeação de José Tomaz de Oliveira ao cargo vago de juiz de direito de Montes Claros. ${ }^{22}$

Para além das obrigações na magistratura, desde cedo José Tomaz envolveuse com o jornalismo montes-clarense, inicialmente colaborando com o jornal $A$

\footnotetext{
${ }^{21}$ VELOSO. A missão "desanalfabetizadora" do jornal Gazeta do Norte, em Montes Claros (1918-1938), 2008.

${ }_{22}$ MINAS GERAES. Belo Horizonte, p. 1, 19 junho, 1898.
} 
Opinião do Norte. ${ }^{23}$ Em 1908, trabalhou na cidade de Dores do Indayá/MG e depois transferiu-se para o Distrito Federal, Rio de Janeiro, onde exerceu cargos de delegado. ${ }^{24}$

No ano de 1912, mês de abril, assumiria o cargo de encarregado de contabilidade da recém-criada Escola de Agricultura de Pinheiros, ${ }^{25}$ sendo exonerado do cargo de suplente de delegado em junho de 1913, ele e mais 24 suplentes: "exonerados por exercerem funcção publica remunerada". ${ }^{26}$

Chamou atenção a reportagem do jornal carioca $O$ Imparcial. Por conta da quantidade de delegados suplente exonerados no dia anterior, entre eles José Tomaz de Oliveira, "houve um verdadeiro 'tempo quente"' pois, continuava a nota: "embora o cargo de suplente de delegado não seja coisa alguma, nem por isso deixa de ser apetecido". A partir da nota, deduzimos que valia a pena ser suplente de delegado, pois, apesar do baixo salário, "a presidencia de theatros, o ingresso gratuito em casas de diversões e outras coisas mais seduzem muito moço elegante". 27

Inferimos que havia compensações que tornavam o cargo de suplente de delegado de polícia um posto interessante para um bacharel afeito aos divertimentos da capital federal. Além de teatros e casas de diversões, como expõe o jornal, sua família pode ter experimentado aspectos da vida moderna que no interior de Minas Gerais não existiam ou eram incipientes. Assim, no futuro, ele e sua família, desembarcariam novamente em Montes Claros com um aporte de outras e novas experiências que inseririam e movimentariam a sociedade, principalmente através das páginas da sua futura Gazeta do Norte.

Por fim, entre nomeações, transferências e exonerações no Rio de Janeiro, em 1917, retornou para Montes Claros como Delegado da Comarca, ${ }^{28}$ para em seguida ser nomeado Juiz Municipal de Montes Claros, ${ }^{29}$ "[...] cargo que abandonou para exercer a advocacia e fundar a Gazeta do Norte em 1918".30

${ }^{23}$ VIANNA. Monographia do municipio de Montes Claros: breves apontamentos históricos, geographicos e descriptivos, 1916.

${ }^{24}$ VELOSO. A missão "desanalfabetizadora" do jornal Gazeta do Norte, em Montes Claros (19181938), 2008. GAZETA DE NOTÍCIAS. Rio de Janeiro, p. 6, 22 janeiro 1911.

${ }^{25}$ O PAIZ. Rio de Janeiro, p. 2, 22 abril 1912.

${ }^{26}$ A NOITE. Rio de Janeiro, p. 3, 18 junho 1913.

27 O IMPARCIAL. Rio de Janeiro, p. 6, 19 junho 1913.

28 JORNAL DO COMMERCIO. Rio de Janeiro, p. 2, 10 março 1917.

${ }^{29}$ O IMPARCIAL. Rio de Janeiro, p. 2, 09 janeiro 1918.

30 VELOSO. A missão "desanalfabetizadora" do jornal Gazeta do Norte, em Montes Claros (19181938), p. 54. 
O envolvimento de bacharéis na imprensa brasileira, caso de José Tomaz de Oliveira, dizia respeito a um processo de desenvolvimento e interiorização da educação, acontecido após a criação das primeiras escolas jurídicas brasileiras (Olinda/PE, Recife e São Paulo, ambas em 1827). Na época, a atividade jurídicopolítica dos bacharéis se manifestou na sociedade como um todo, pois eram tidos como aptos a exercerem as mais diversas funções públicas, haja vista a quantidade de analfabetos na população. Nota-se na história do Direito, que muitos bacharéis eram jornalistas e literatos e, em função disso, tornavam-se figuras influentes nas cidades. ${ }^{31}$

Caracterizando a Gazeta do Norte, o memorialista Nelson Vianna a definiu como um "jornal noticioso, publicando também comentários sobre fatos atuais, contos, crônicas, poesias, notas sociais, editais e anúncios, vem acompanhando o progresso, continuando o programa traçado, em atuação moderada e simpática". ${ }^{32}$

\section{ARI DE OLIVEIRA: A FORJA DO SPORTSMAN MONTES-CLARENSE}

Ari de Oliveira nasceu em Montes Claros no ano de 1900. No Rio de Janeiro, concluiu o ano letivo de 1912 no Collegio Maia,33 porém, anteriormente esteve, por anos, vinculado ao Colégio Militar Paula Freitas. Frequentar essa escola no início do século $\mathrm{XX}$, aponta-nos para um significativo sensibilizador do ímpeto esportivo de Ari de Oliveira. Segundo Pereira, naquela época, além de no Rio de Janeiro já haver a prática do elitista futebol como um jogo promotor de higiene e saúde, e que atraía cada vez mais a mocidade carioca para a sua prática, colégios de orientação inglesa, como o Colégio Latino Americano, disputavam jogos contra equipes da Associação Atlética do Colégio Paula Freitas, fundada em 1905. 34

Tal indicação de Pereira pode ser notada no jornal Gazeta de Notícias, quando anunciou a inauguração do campo de futebol da "Associação Athletica do Collegio

\footnotetext{
${ }^{31}$ SANTOS; CASIMIRO. Memória e direito: as origens do bacharelismo liberal no Brasil Império (1822-1889), 2012.

32 VIANNA. Efemérides montesclarenses, p. 331.

${ }^{33}$ CORREIO DA MANHÃ. Rio de Janeiro, p. 4, 23 dezembro 1912.

${ }^{34}$ PEREIRA. Footballmania: uma história social do futebol no Rio de Janeiro (1902-1938), 1998.
} 
Paula Freitas" para o dia 1ำ de julho de 1906, "sendo nessa ocasião jogado um macht official com o $1^{\text {o }}$ team do acreditado Colegio Latino-Americano". 35

Se no futebol o Colégio Paula Freitas já se fazia presente com uma equipe desde 1905, com treinos e amistosos no campo da sua associação, na rotina da escola a "educação física" também era valorizada pela sua direção. 0 folhetim Gazeta de Notícias apurou que em 1906 "rapazes, alumnos do Collegio Paula Freitas, com a maior dedicação e interesse, entrega-se aos exercicios preliminares de halteres durante a aula de gymnastica que alli funcciona 4 vezes por semana, com a maior regularidade". ${ }^{36}$ Esta era a escola que receberia Ari de Oliveira, por ocasião da mudança da sua família, do sertão norte-mineiro para a Capital do país.

Retornou com a família para Montes Claros iniciando sua vida profissional, sempre vinculado à Gazeta do Norte. 0 memorialista Hermes de Paula descreve Ari de Oliveira como um "jornalista impetuoso, irrequieto, [e que] em sua juventude movimentou a cidade nos setores político, social e esportivo". ${ }^{37}$

Vale destacar que no início do século XX, período em que a família de Ari de Oliveira residiu no Rio de Janeiro, capital do país e principal centro receptor das novidades europeias, “[...] os esportes foram [eram] sempre encarados, em vários sentidos, como divertimentos "úteis". Eram claramente concebidos como uma forma de identificação com o "mundo civilizado europeu", de demonstração de avanço ou constatação do atraso social. ${ }^{38}$

Sobre sua trajetória profissional, Hermes de Paula o considerou um "intelectual de grande espontaneidade e vivaz",39 que publicou diversas poesias e escreveu o livro A milho e carvão, livro que relata as aventuras de um caixeiro viajante nos sertões. Profissionalmente, figurou como gerente do jornal Gazeta do Norte por muitos anos até se transferir de Montes Claros para Uberaba-MG.

Além das suas funções na Gazeta do Norte, primeiro como gerente e depois como gerente-redator, Ari, que foi figura constante nos primórdios da história do futebol montes-clarense, notabilizou-se pela postura de um sportsman, tipo de

\footnotetext{
35 GAZETA DE NOTÍCIAS. Rio de Janeiro, p. 5, 16 junho 1906.

${ }^{36}$ GAZETA DE NOTÍCIAS. Rio de Janeiro, p. 6, 4 maio 1906.

${ }^{37}$ PAULA. Montes Claros: sua história sua gente seus costumes, p. 176.

${ }^{38}$ MELO. O esporte como forma de lazer no Rio de Janeiro do século XIX e década inicial do XX, p. 54.

39 PAULA. Montes Claros: sua história sua gente seus costumes, p. 231.
} 
personagem fundamental no desenvolvimento de uma vivência moderna. No caso de Ari de Oliveira, o futebol.

Sobre o sportman na história do futebol, podemos inferi-lo como um promotor de um novo hábito, e sobre esta atividade dita moderna, podemos dizer que

[...] o campo de futebol era a representatividade de uma simbologia anteposta pelas elites. Nesse espaço predeterminado por um grupo, a heterogeneidade não quis ser percebida entre um determinado grupo de praticantes da pelota, os sportsmen. É como se eles tivessem fechado os olhos para as diversificadas formas da praxe do futebol e de seus praticantes. É claro que não acredito nisso de forma vil e rígida, aparentando que os sportsmen eram sujeitos que predeterminavam sempre suas ações sociais e tinham controle total de sua cultura. Eles não podiam perceber tudo isso como nós o fazemos. Esse era o grande entrave da percepção que os sportsmen tinham da sociedade em que viviam. A memória que eles deixaram escrita é a percepção deles do seu mundo. A divisão social existe[nte] no discurso é muito forte, tanto que eles não permitiam as classes subalternas participarem da construção dessa história. Porém, ao mesmo tempo, a segregação social não é tão rija, pois eles não impediam a participação de sujeitos de outras classes e de homens negros na formação do futebol. 40

Possivelmente, Ari de Oliveira se encaixa na característica de um sportman montes-clarense, pois suas ações se pautaram no desenvolvimento e na prática propriamente dita do futebol de Montes Claros, atuando nas pioneiras equipes do Mineiro Sport Club, America Sport Club e Montesclaros Sport Club, por dez anos identificados nas páginas dos jornais.

Apesar de não ter participado da fundação da primeira equipe local - o Mineiro Foot-Ball Club, em $1916-,{ }^{41}$ porque sua família ainda não havia retornado à Montes Claros, Ari de Oliveira chegou a fazer parte da equipe precursora. Em seu livro de memórias, o escritor Ciro dos Anjos diz que, Ari de Oliveira, "rapaz ledo, bonito e namorador, [...] luzia como um sol no time branco do Mineiro". ${ }^{42}$ Porém, foi um dos responsáveis pela cisão no Mineiro que resultou na fundação da segunda equipe de futebol de Montes Claros, o America Foot-Ball Club (Fig. 2), em fevereiro de 1917.43

\footnotetext{
40 PINTO. A formação dos times de futebol proletário e as intervenções das elites: a construção da história do futebol cearense e os conflitos sociais em torno da bola (1919-1938), p. 1.

${ }^{41}$ MONTES CLAROS. Montes Claros, p. 1, 02 outubro 1916.

42 ANJOS. A menina do sobrado, p. 182.

${ }^{43}$ MONTES CLAROS. Montes Claros, p. 2, 15 fevereiro 1917.
} 


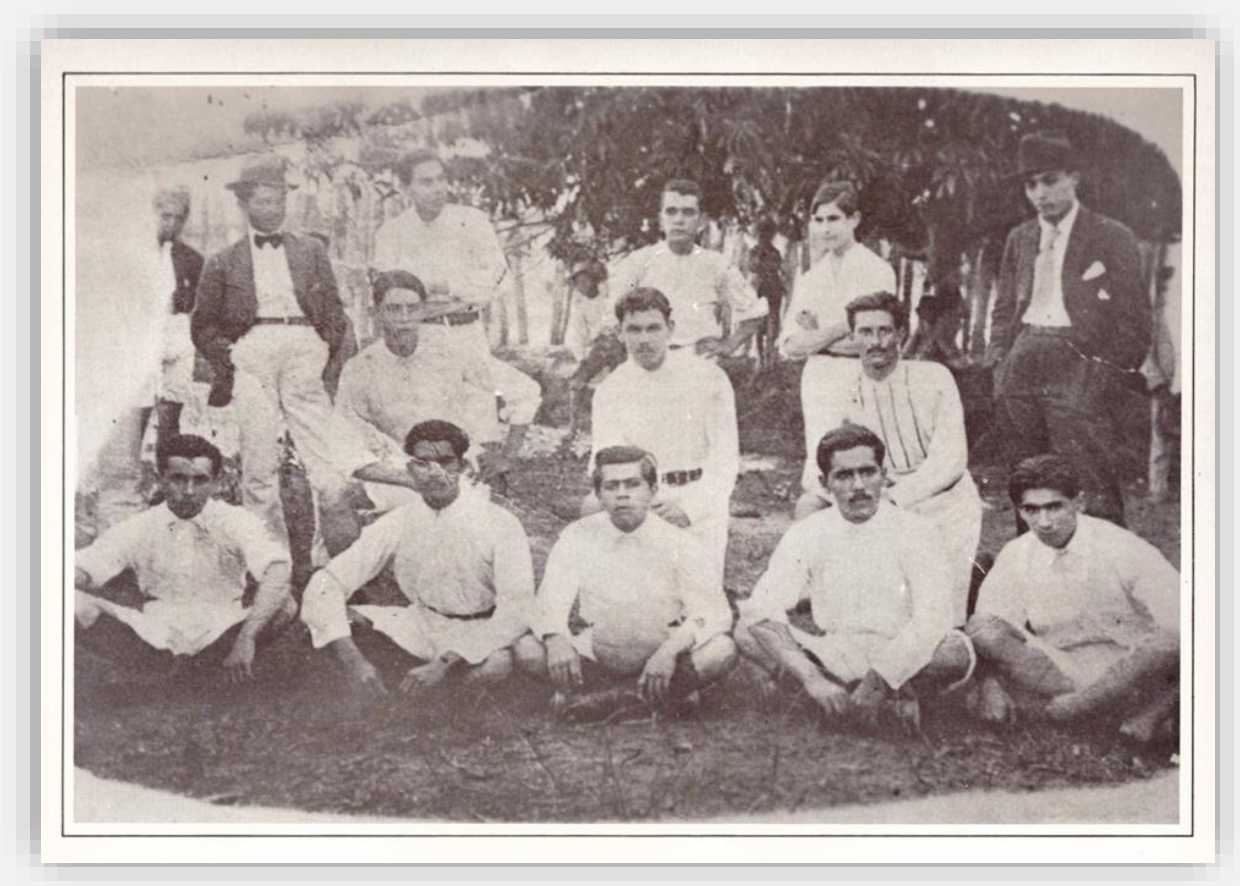

Fig. 2 - America Foot-ball Club, fundado em 1917. Entre os atletas fundadores estão os irmãos Ari e Jair de Oliveira, herdeiros do jornal Gazeta do Norte. Revista Montes Claros, agosto de 1940, p. 2.

Os embates entre o Mineiro e o America, por anos, animaram e compuseram as páginas dos jornais Montes Claros e Gazeta do Norte. Como sabido, ambas equipes representavam um dos dois lados políticos da cidade, assim como os próprios jornais. Do lado político liderado pela família Alves, estavam o Mineiro Foot-Ball Club e o jornal Montes Claros; e do lado da família dos Prates, o America Foot-Ball Club e a Gazeta do Norte. Obviamente, Ari de Oliveira, militou ladeando a Gazeta do Norte do seu pai e, sistematicamente em vários momentos, tanto Ari quanto o seu irmão Jair figuram como atletas do America. Ademais, desempenharam as funções de capitão da equipe, Ari, e secretário do clube, Jair.

Podemos assinalar que os jovens herdeiros da Gazeta do Norte, ao retornarem dos seus estudos no Rio de Janeiro e Recife, estiveram à frente da organização e efetivação de uma das duas equipes da cidade, possivelmente difundindo o que acessaram nos dois centros adiantados onde residiram e estudaram na infância e adolescência. 
Com a extinção dos algozes esportivos/políticos, a cidade viveu um hiato de insignificância futebolística, se comparado aos tempos de Mineiro e America. A fundação do Montesclaros Sport Club, em 1924, inaugurou outro período do futebol local e, mais uma vez, destacam-se Ari e Jair de Oliveira, notadamente o Ari. Na fundação do Montesclaros, Ari desempenhou a função de Director-sportivo e Jair a de secretário da equipe, além de futebolistas.

Ari de Oliveira marcou o gol mais importante do ano de 1924, quando o Montesclaros recebeu o Bocayuva Sport Club, equipe originária da homônima cidade, disputaram uma partida amistosa que "parou" a cidade. 0 evento pretendia demonstrar a civilidade e a nobreza que o futebol pregava, assim "foram programadas visitas e passeios de automóvel, pela cidade, em companhia de rapazes do nosso clube e senhoritas da nossa melhor sociedade". Entretanto, segundo o cronista, após o gol marcado por Ari de Oliveira, segundo o jornal, "a assistencia portou-se inconvenientemente invadindo por duas vezes, o campo, pelo que merece a nossa mais áspera censura". 44

Para demonstrar a posição diferenciada de Ari de Oliveira e a liderança exercida sobre os demais, transcrevemos o lance que resultou no pênalti a favor do Montesclaros, com sua atuação decisiva perante a marcação do árbitro da partida:

Os nossos voltam a atacar e quando, na área perigosa, Henriques quer passar por Paixão, este lhe aplica um calço pelas costas; o juiz apita falta maxima, porem, quer que o pontapé livre seja batido do canto da área, de onde a penalidade foi cometido. 0 nosso capitão faz-lhe ver o engano e ele manda a bola para a marca da maxima penalidade. Ary approxima-se da esfera. 0 juiz apita. A's 6,10, cinco minutos antes de terminar a partida, a bola vaza o arco bocayuvense. A assistencia delira, invadindo novamente o campo, só recuando devido aos esforços dos dirigentes do "montesclaros". 45

As atuações de Ari de Oliveira, dentro e fora do campo, o alçava a uma posição de destaque no cenário esportivo local e sua presença seria sentida durante toda a existência do Montesclaros Sport Club. No jogo mais importante de 1926, esteve entre os vencidos pela equipe do $15^{\circ}$ Regimento de Cavalaria em passagem por

\footnotetext{
${ }^{44}$ GAZETA DO NORTE. Montes Claros, p. 2, 06 dezembro 1924.

${ }^{45}$ GAZETA DO NORTE. Montes Claros, p. 2, 06 dezembro 1924.
} 
Montes Claros $^{46}$ e nas excursões futebolísticas para as cidades de Corinto $^{47}$ e Curvelo, ${ }^{48}$ em agosto e outubro de 1927, Ari foi um dos jogadores e negociadores dos encontros. Por fim, em edição do dia 31 de dezembro de 1927b, a Gazeta do Norte anunciaria um jogo entre sócios do Montesclaros, entre os Velhos, equipe onde se encontrava Ari de Oliveira, e os Moços. ${ }^{49}$

Certo é que, após este último jogo, a Gazeta do Norte só noticiaria novamente o futebol local em fevereiro de 1929, quando surgiu o Montesclaros Foot-ball Club. Nesse ínterim, o nome de Ari de Oliveira não mais constaria em qualquer convocação para o futebol de Montes Claros e, profissionalmente, assumiria em julho de 1928 a função de redactor-gerente da Gazeta do Norte.

Faleceu em fevereiro de 1960 na cidade de Uberaba/MG, onde residia desde os anos 1930 e fundara o Jornal de Uberaba e a revista Zebu. À época da sua morte, a Gazeta do Norte publicou reportagem enaltecendo seus feitos profissionais, mas, também destacou que "bem jovem ainda, ele foi animador dos esportes, tornando-se figura muito querida à frente do América Futebol Clube, desta cidade - que tinha o seu principal elemento".50

O texto do jornal lembra sua atuação como "animador dos esportes", uma expressão sugestiva para alguém que, não só praticava, como também promovia o esporte em Montes Claros, capitaneando o América F. C., fundado em 1917. Segundo a gazeta, para além das suas atividades no trabalho, "durante muitos anos, o seu nome esteve ligado a todos os movimentos de inteligencia e de cultura que surgiram em Montes Claros, sendo destacada a sua participação em centros literarios, jornais, revistas e clubes recreativos". 51

\section{CONCLUSÕES}

Entendido que a cidade de Montes Claros seguiu o modelo em voga no país, de instituição paulatina dos aspectos sociais advindos da modernidade europeia,

\footnotetext{
${ }^{46}$ GAZETA DO NORTE. Montes Claros, p. 1, 12 maio 1926.

47 GAZETA DO NORTE. Montes Claros, p. 1, 31 agosto 1927.

48 GAZETA DO NORTE. Montes Claros, p. 1, 19 outubro 1927.

${ }^{49}$ GAZETA DO NORTE. Montes Claros, p. 1, 31 dezembro 1927.

50 GAZETA DO NORTE. Montes Claros, p. 1, 28 fevereiro 1960.

51 GAZETA DO NORTE. Montes Claros, p. 1, 28 fevereiro 1960.
} 
conclui-se que, Ari de Oliveira, devido ao seu envolvimento como atleta amador e dirigente das equipes que participara em Montes Claros, em pouco mais de 10 anos após retornar do Rio de Janeiro, lugar onde conviveu numa sociedade em ebulição esportiva no início do século XX, constituiu-se num sportsman local, refletindo o esporte da cidade grande para o interior, praticando e promovendo o futebol.

Se Charles Miller, Oscar Cox, Zuza Ferreira, Guilherme de Aquino, entre outros, são considerados os fundadores e desenvolvedores do futebol em suas respectivas cidades e, por conseguinte, tornaram-se historicamente respeitados sportsmen, seguramente, outros personagens foram surgindo nas mais diversas localidades brasileiras.

No caso de Montes Claros, não se identifica uma personalidade que tenha estudado e retornado da Europa com materiais e informações sobre o futebol e que, em função disso, tenha encarnado o símbolo do mito fundador esportivo local. Ainda assim, a história de Ari de Oliveira se aproxima da biografia dos citados sportsmen, pois, graças a sua experiência formativa no Rio de Janeiro, tornar-se-ia um agitador esportivo da cidade ao se envolver diretamente com o futebol montes-clarense no início do século XX.

Não é possível afirmar que Ari de Oliveira tenha sido o primeiro sportsman da cidade, mas, é plausível inferir que sua atuação na promoção do futebol local foi destacada, porque foi observado nas fontes acessadas inúmeras passagens comprobatórias da sua rotina como amador de futebol, fosse como atleta ou dirigente. Certamente, o conhecimento adquirido no Rio de Janeiro, somado ao fato de escrever e dirigir com seu pai o jornal Gazeta do Norte, o induziu a manter um comportamento próprio dos sportsmen. Se, antes dele, existira em Montes Claros alguém com essas características, nem de longe rivalizou com Ari de Oliveira. 


\section{REFERÊNCIAS}

ANJOS, Ciro dos. A menina do sobrado. Rio de Janeiro: José Olímpio, 1979.

BARBOSA, Marialva. História cultural da imprensa: Brasil 1900-2000. Rio de Janeiro: Mauad X, 2007.

DIAS, Cleber. O esporte e a cidade na historiografia brasileira: uma revisão crítica. Tempo, v. 19, n. 34, p. 33-44, 2013.

FERNADEZ, Renato Lanna. Futebol, identidades e representações - caso do Fluminense Football Club. In: Simpósio Nacional de História, 24, 2009, Fortaleza. Anais... Disponível em: https://anais.anpuh.org/?p=14575. Acesso em: 18 abr. 2018.

GIDDENS, Anthony. As consequências da modernidade. São Paulo: Unesp, 1991.

JEUKEN, Bruno. Esporte na primeira república: a história do espetáculo. Revista de História, São Paulo, n. 176, p.1-10, 2017.

LIMA, Eduardo José Silva. Da chegada a institucionalização: os primeiros passos do futebol pernambucano. In: Simpósio Nacional de História, 26, 2011, São Paulo. Anais... Disponível em: https://bit.ly/2RK8xcR. Acesso em: 12 dez. 2019.

MÁXIMO, João. Memórias do futebol brasileiro. Estudos Avançados, v. 13, n. 37, p. 179-188, 1999.

MELO, Victor Andrade de. O esporte como forma de lazer no Rio de Janeiro do século XIX e década inicial do XX. In: MARZANO, Andrea; MELO, Victor Andrade de. (Orgs.). Vida divertida: histórias do lazer no Rio de Janeiro (1830-1930). Rio de Janeiro: Apicuri, 2010.

MELO, Victor Andrade de. Entre a elite e o povo: o sport no Rio de Janeiro do século XIX (1851-1857). Tempo, v. 21, n. 37, p. 208-229, 2015a.

MELO, Victor Andrade de. O esporte: uma diversão no rio de janeiro do século XIX. Revista Brasileira de Estudos do Lazer, v. 2, n. 3, p. 49-66, 2015b.

MELO, Victor Andrade de. Evidência e especulação: a origem do futebol no Rio de Janeiro (1898-1902). Movimento, v. 23, p. 919-934, 2017.

MELO, Victor Andrade de; SANTOS, Flávia da Cruz. Deslizando rumo ao progresso: a patinação em São Paulo (1877-1912). Movimento, v. 23, p. 171184, 2017.

PAULA, Hermes Augusto. Montes Claros: sua história sua gente seus costumes. Belo Horizonte: Minas Gráfica Editora, 1957.

PAULA, Hermes Augusto. Montes Claros: sua história sua gente seus costumes. 2. ed. Belo Horizonte: Minas Gráfica Editora, 1979.

PEREIRA, Leonardo Affonso de Miranda. Footballmania: uma história social do futebol no Rio de Janeiro (1902-1938). Tese (Doutorado em História). Instituto de Filosofia e Ciências Humanas da Universidade Estadual de Campinas, Campinas, 1998. 
PINTO, Rodrigo Márcio Souza. A formação dos times de futebol proletário e as intervenções das elites: a construção da história do futebol cearense e os conflitos sociais em torno da bola (1919-1938). In: Simpósio Nacional de História, 24, 2007, São Leopoldo. Anais... Disponível em: https://bit.ly/38vA87F. Acesso em: 18 mar. 2018.

SANTOS, Daniella Miranda; CASIMIRO, Ana Palmira Bittencourt Santos. Memória e direito: as origens do bacharelismo liberal no Brasil Império (18221889). Educação, gestão e sociedade, v. 2, n. 5, 2012.

SANTOS, Henrique Sena. Entre negros e brancos: considerações sobre a formação da cultura futebolística em Salvador, 1901-1920. Recorde, v. 2, n. 1, p. 1-28, 2009.

SEVCENKO, Nicolau. A capital irradiante: técnica, ritmos e ritos do Rio. In: . (Org.). História da vida privada no Brasil. São Paulo: Companhia das Letras, v. 3, 1998.

SILVA, Luciano Pereira da. O futebol e o início da diversão esportivizada em Montes Claros-MG. Licere, v. 16, n. 1, mar. 2013.

VELOSO, Geisa Magela. A missão "desanalfabetizadora” do jornal Gazeta do Norte, em Montes Claros (1918-1938). Tese (Doutorado em Educação). Faculdade de Educação da UFMG, Belo Horizonte, 2008.

VIANNA, Nelson. Efemérides montesclarenses. Rio de Janeiro: Pongetti, 1964.

VIANNA, Urbino de Souza. Monographia do municipio de Montes Claros: breves apontamentos históricos, geographicos e descriptivos. Belo Horizonte: Imprensa Oficial do Estado de Minas Gerais, 1916. 